\title{
Magnetic Hysteresis in Young Mid-Ocean Ridge Basalts: Dominant Cubic Anisotropy?
}

\author{
Jeff Gee ${ }^{1}$ and Dennis V. Kent \\ Lamont-Doherty Earth Observatory, Palisades, NY 10964
}

\begin{abstract}
Magnetic hysteresis data from young mid-ocean ridge basalts include samples with saturation remanence to saturation magnetization (Mrs/Ms) ratios greater than 0.5 , the theoretical limit for an assemblage of single domain grains with uniaxial anisotropy. Under the usual assumption of dominant uniaxial anisotropy, the narrow single domain grain size distribution implied by these high $\mathrm{Mrs} / \mathrm{Ms}$ values is difficult to reconcile with petrographic and remanence data that suggest the presence of larger multidomain grains. Dominant cubic anisotropy provides a plausible explanation for the high Mrs/Ms ratios, and if generally valid, requires reinterpretation of granulometric and domain state inferences made from hysteresis data.
\end{abstract}

The magnetic properties of a ferromagnetic material are strongly dependent on domain state and hence particle size. Although a variety of magnetic parameters have been used, hysteresis data are perhaps the most common means used to characterize the domain state and infer the average magnetic grain size. In particular, a plot of the ratio of the remanent coercivity to coercivity $(\mathrm{Brc} / \mathrm{Bc})$ versus the ratio of saturation remanence to saturation magnetization (Mrs/Ms) is widely used to determine the average domain state of (titano)magnetite-bearing rocks [Day et al., 1977]. A single domain (SD) endmember with an Mrs/Ms ratio of $\sim 0.5$ is invariably assumed, based on the theoretical limit for uniaxial anisotropy [Stoner and Wohlfarth, 1948].

We have commonly encountered samples of young midocean ridge basalts (MORB) with Mrs/Ms ratios significantly higher than the theoretical limit of $\sim 0.5$ (Fig. 1). The majority of our dredged samples are from the northern East Pacific Rise (near $12^{\circ} \mathrm{N}$; Gee and Kent, 1994) although a smaller number of MORB samples from the Southeast Indian Ridge and MidAtlantic Ridge were also measured. The sample collection comprises fragments of pillow lavas and sheet flows collected generally within $5-10 \mathrm{~cm}$ of the chilled margin. Hysteresis parameters were determined on an alternating gradient force magnetometer (Micromag 2900) using a maximum field of $1.0 \mathrm{~T}$. The Mrs/Ms ratios were calculated following the standard correction for the high field paramagnetic slope by least-squares regression of the data from 0.7-1.0 T. With this correction, the MORB samples typically have Mrs/Ms values of $0.35-0.65$, with approximately half of the samples having an $\mathrm{Mrs} / \mathrm{Ms}$ ratio $>0.5$ (Fig. 1).

\footnotetext{
${ }^{1}$ Now at Scripps Institution of Oceanography, La Jolla, California.
}

\section{Copyright 1995 by the American Geophysical Union.}

High Mrs/Ms ratios have also been reported in other studies of MORB samples. For example, hysteresis data (measured on a vibrating sample magnetometer) from a suite of basaltic samples collected during DSDP Leg 49 on the Mid-Atlantic Ridge [Day et al., 1978] show a large range in Mrs/Ms ratios and include values as high as 0.68 (Fig. 1). Although these authors did not comment on the significance of such high Mrs/Ms ratios, the trend of the combined data on a bilogarithmic plot (Fig. 1 inset) strongly suggests a range of grain sizes with a SD endmember having an Mrs/Ms ratio higher than the maximum value observed (best fit power law gives Mrs/Ms $\sim 0.84$ at $\mathrm{Brc} / \mathrm{Bc}=1.04$ ).

The high Mrs/Ms ratios of our samples caused us to reexamine the slope correction used to determine the saturation magnetization. The paramagnetic slope may be independently estimated from the iron content of the rock and an estimate of the percentage of ferromagnetic material in the sample (Fig. 2). We used the $\mathrm{FeO}^{*}$ (total iron as $\mathrm{FeO}$ ) content of the glass and a $\mathrm{Fe}^{3+} / \mathrm{Fe}_{\text {total }}$ ratio of 0.15 suitable for MORB pillow interiors [Christie et al., 1986] to calculate the maximum paramagnetic slope $\left(1 \mathrm{wt} \% \mathrm{FeO}=2.07 \times 10^{-8} \mathrm{~m}^{3} / \mathrm{kg} ; 1 \mathrm{wt} \% \mathrm{Fe}_{2} \mathrm{O}_{3}=2.26 \mathrm{x}\right.$ $10^{-8} \mathrm{~m}^{3} / \mathrm{kg}$; Collinson, 1983). The saturation magnetization value determined from the standard slope correction was then used to estimate the volume percentage of titanomagnetite $\left(\mathrm{Fe}_{3-\mathrm{x}} \mathrm{Ti}_{\mathrm{x}} \mathrm{O}_{4} ; 0<\mathrm{x}<1\right)$, assuming a composition of $\mathrm{x}=0.6$ (TM60) with Ms $=27.4 \mathrm{Am}^{2} / \mathrm{kg}$ [Moskowitz, 1993]. The majority of samples have $0.5-1.5 \%$ equivalent TM60 grains,

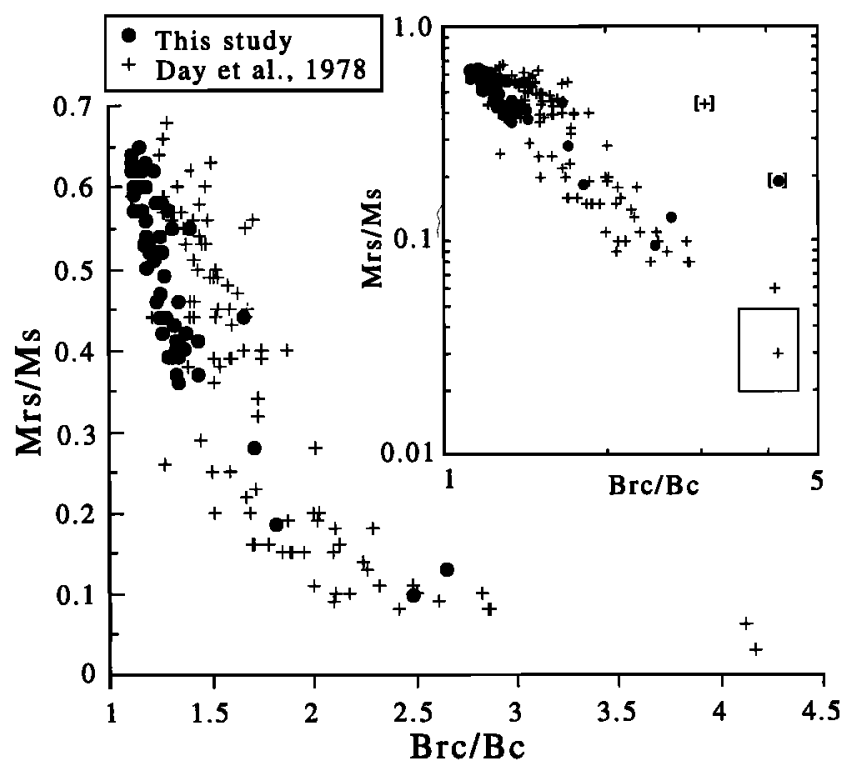

Figure 1. Hysteresis parameters of mid-ocean ridge basalt samples. Bilogarithmic plot (inset) shows trend of basalt data toward SD Mrs/Ms value $>0.5$. Box indicates hysteresis parameters of multidomain TM50-TM60 [Day et al., 1976]. Best fit power law for MORB data excluding two points in brackets (not shown in main figure): $\mathrm{Mrs} / \mathrm{Ms}=0.916 * \mathrm{Brc}^{-\mathrm{Bc}^{-2.27}}$. 


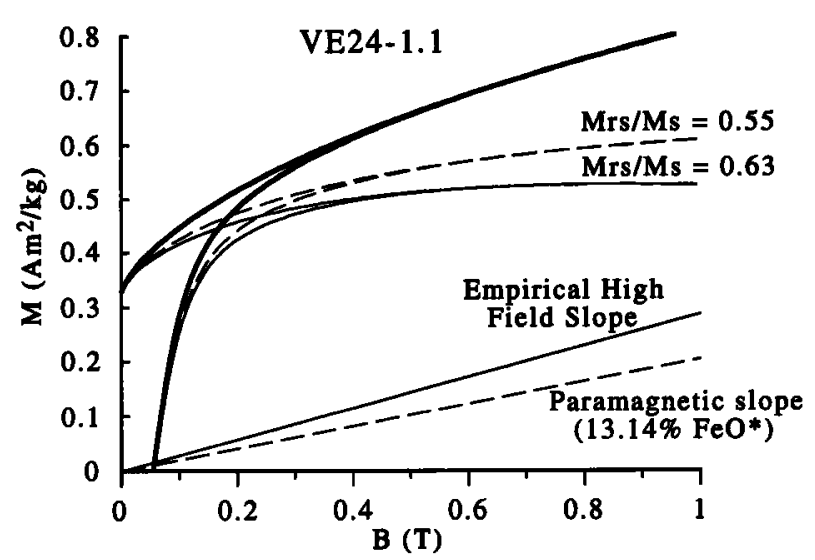

Figure 2. Slope correction of hysteresis data for representative fine-grained basalt sample from the East Pacific Rise (see also Fig. 3a). Uncorrected (heavy line), standard slope corrected (thin line) and paramagnetic slope corrected (dashed line) hysteresis data are shown. Lines indicate high field slope determined by least squares fit of data from 0.7-1.0 $\mathrm{T}$ (solid) and paramagnetic slope derived from $\mathrm{FeO}^{*}$ content (dashed) as described in text.

indicating that more than $90 \%$ of the iron is partitioned into paramagnetic phases. The high field slopes calculated with this method are invariably lower than the empirically determined slopes, resulting in lower calculated Mrs/Ms ratios (Fig. 2). Discrepancies between the two high field slopes, which differ more for finer grained samples, may reflect incomplete saturation although higher field data (to 5T; C. HUNT, pers. comm.) for the sample in Figure 2 yield only a slightly lower $\mathrm{Mrs} / \mathrm{Ms}$ value (0.49). As any superparamagnetic contribution would result in underestimation of the $\mathrm{Mrs} / \mathrm{Ms}$ ratio, the Mrs/Ms values from these two slope correction methods likely bracket the true value in most cases.

Depending on the slope correction employed, ten to fifty percent of the present sample collection has $\mathrm{Mrs} / \mathrm{Ms}$ ratios > 0.5. These Mrs/Ms ratios (up to $\mathbf{0 . 6 2 - 0 . 6 5}$ ) are comparable to or higher than the values obtained on well-sized (0.02-0.05 $\mu \mathrm{m})$ synthetic SD titanomagnetites [Özdemir and $O^{\prime} R e i l l y$, 1981]. Under the assumption of dominant uniaxial anisotropy, even Mrs/Ms ratios of 0.5 imply a grain size distribution entirely within the SD size range. Both theoretical [Moskowitz, 1980; Moskowitz and Halgedahl, 1987; Dunlop, 1990] and experimental [Soffel, 1971] studies suggest that the critical largest diameter for SD particles is on the order of $0.6 \mu \mathrm{m}$ for stoichiometric titanomagnetite. For reasons outlined below, however, we suggest that the effective grain size distribution in these natural basalt samples is unlikely to be confined entirely within the narrow size range (0.08-0.6 $\mu \mathrm{m}$; Dunlop, 1990) for SD behavior.

Petrographic observations provide direct evidence of grains larger than the SD size range in even the finest grained basalt samples. For example, two basalt samples with Mrs/Ms ratios $>0.5$ shown in Figure 3 both have abundant $2-5 \mu \mathrm{m}$ skeletal grains, with rare grains as large as $-20 \mu \mathrm{m}$ in size. In terms of magnetic properties, the effective grain size of such optically homogeneous quench crystals is undoubtedly smaller than the maximum linear dimension of these grains; however, a reasonable estimate of the effective magnetic grain size is provided by the dimension of equant areas (e.g., terminations of the cruciform titanomagnetite grains). There is an abundance of equant areas larger than $1 \times 1 \mu \mathrm{m}$, with areas as large as $5 \times 5 \mu \mathrm{m}$.
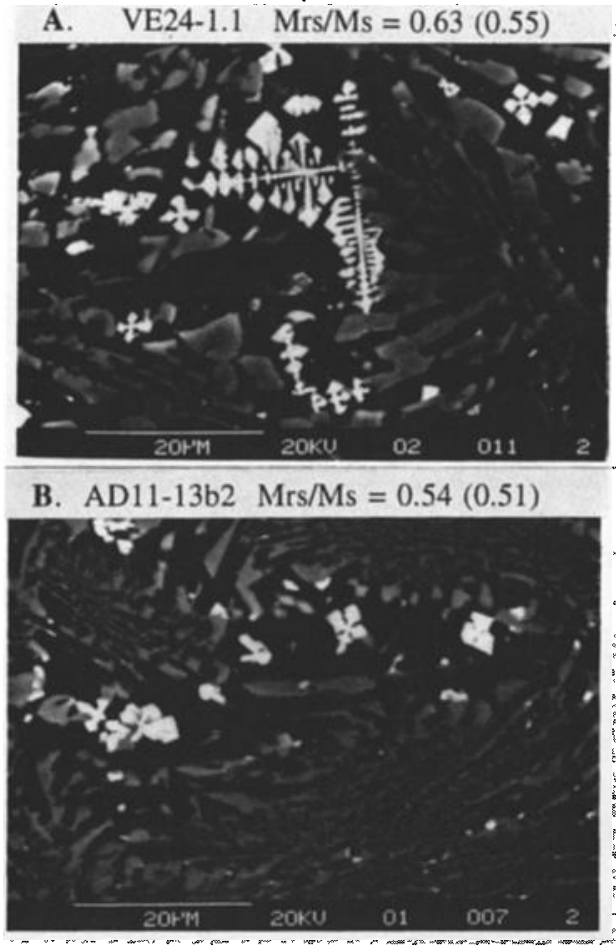

Figure 3. Backscatter electron images (x1600) illustrating representative grain size distribution of titanomagnetite (white) in two basalt samples. Mrs/Ms values are indicated for the standard and paramagnetic (in parentheses) slope corrections. Curie temperatures are $175^{\circ}-210^{\circ} \mathrm{C}$ (a) and $\sim 110^{\circ} \mathrm{C} \mathrm{(b)}$.

not uncommon. In addition, both samples have numerous finer grains as small as $\sim 0.1 \mu \mathrm{m}$, the nominal resolution limit of the optical microscope, implying the presence of even finer grains. The grain size distribution in these samples therefore spans more than two orders of magnitude, which is broader and extends significantly beyond the SD size range $(0.08-0.6 \mu \mathrm{m})$. It follows that the highest observed $\mathrm{Mrs} / \mathrm{Ms}$ ratios constituie

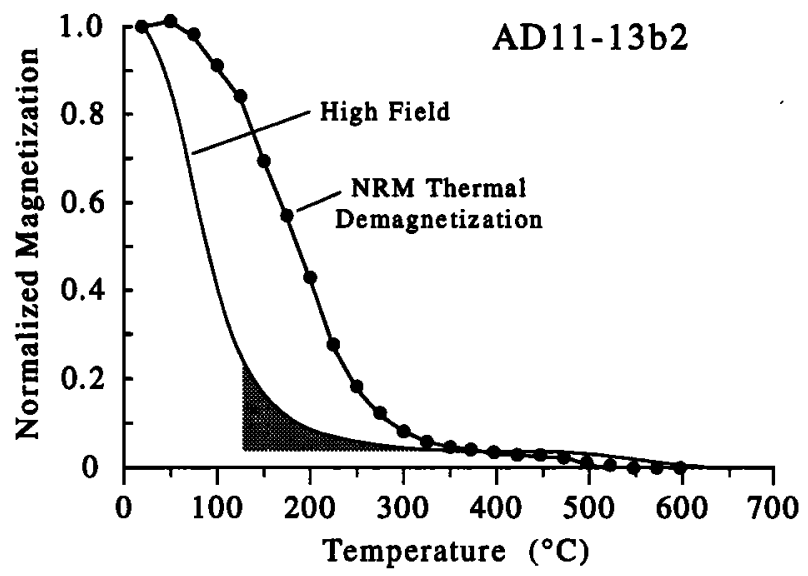

Figure 4. Temperature dependence of natural remanent magnetization (NRM) and high field magnetization $(0.15 \mathrm{~T}$; heating in air at $25^{\circ} \mathrm{C} /$ minute) for sample AD11-13b2 (shown in Fig. 3b). NRM unblocking above dominant Curie point interpreted as carried by an oxidized SD fraction, with minor expression in the high field magnetization curve (stippled region). High field magnetization curve to $200^{\circ} \mathrm{C}$ at heating rate of $5 \%$ minute is essentially reversible, with extrapolated Curie points of $111^{\circ} \mathrm{C}$ and $114^{\circ} \mathrm{C}$ for the heating and cooling curves. 
Table 1: Material Constants and Anisotropy Energies for Titanomagnetites

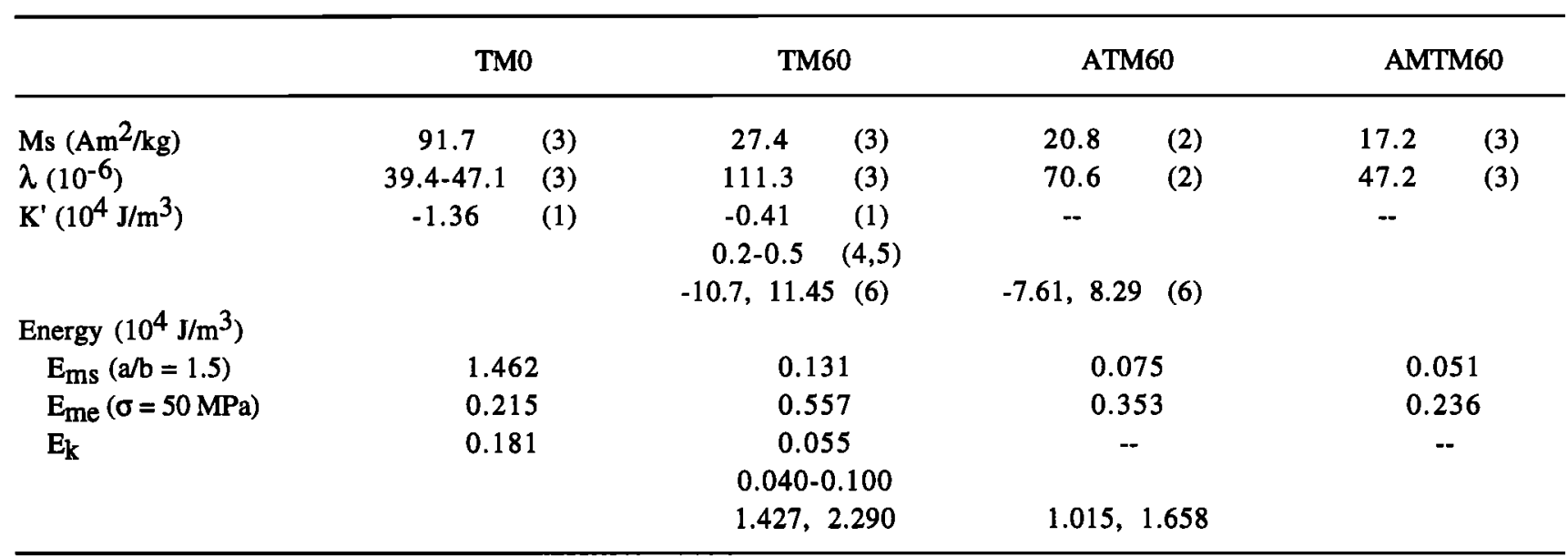

$\mathrm{ATM} 60=\mathrm{Fe}_{2.3} \mathrm{Al}_{.1} \mathrm{Ti}_{.6} \mathrm{O}_{4} . \mathrm{AMTM}_{60}=\mathrm{Fe}_{2.2} \mathrm{Al}_{.1} \mathrm{Mg}_{.1} \mathrm{Ti}_{6} \mathrm{O}_{4}$.

References: (1) Syono [1965], TM60 data interpolated; (2) Ozdemir and Moskowitz [1992]; (3) Moskowitz [1993]; (4) Sahu and Moskowitz [in press] for TM61; (5) Kakol et al. [1991] extrapolated from TM55 measurement; (6) Özdemir and O'Reilly [1981], $K^{\prime}$ inferred from hysteresis data on dispersed synthetic grains.

Energy terms [O'Reilly, 1984] are for randomly oriented assemblage $\left(\sin ^{2} \theta=2 / 3\right)$. Magnetostatic $\left(E_{\mathrm{ms}}\right)=0.5 *\left(\mathrm{~N}_{\mathrm{a}}-\mathrm{N}_{\mathrm{b}}\right) *$ $\mathrm{Ms}^{2 *} \sin ^{2} \theta$. Magnetoelastic $\left(\mathrm{E}_{\mathrm{me}}\right)=1.5^{*} \lambda^{*} \sigma^{*} \sin ^{2} \theta$. Magnetocrystalline $\left(\mathrm{E}_{\mathrm{K}}\right)=\mathrm{K}^{\prime} / 5\left(\mathrm{~K}^{\prime}>0\right) ; \mathrm{Ek}=2 * \mid \mathrm{K}^{\prime} / 15\left(\mathrm{~K}^{\prime}<0\right)$.

only a minimum estimate for the Mrs/Ms ratio of the SD endmember.

High field and remanence data from these samples also support the presence of relatively large multidomain grains. Substantial remanence unblocking often occurs at temperatures above the dominant Curie temperature; for the sample in Figure $3 \mathrm{~b}, 70 \%$ of the remanence remains after thermal demagnetization at $150^{\circ} \mathrm{C}$ whereas the high field magnetization is reduced to only $\sim 15 \%$ at this temperature (Fig. 4). This systematic elevation of remanence unblocking relative to the dominant Curie temperature has been interpreted as a result of preferential oxidation of the finer grained, remanence-carrying SD fraction whereas a volumetrically dominant, less oxidized multidomain fraction hardly contributes to the remanence but dominates the high-field magnetization [Kent and Gee, 1994]. We therefore conclude that even the finest grained basalt samples (ie. those with $\mathrm{Mrs} / \mathrm{Ms}>0.5$ ) must contain both $\mathrm{SD}$ and multidomain (and possibly superparamagnetic) grains.

The apparent contradiction between the effective grain size inferred from hysteresis properties and that derived from other magnetic/petrographic techniques might suggest that the critical size for SD titanomagnetites is simply larger than $0.6 \mu \mathrm{m}$. However, such a shift in the effective SD/multidomain grain size boundary would not account for the systematic elevation of unblocking temperatures relative to Curie temperatures in these MORB samples. Most importantly, for a randomly oriented assemblage of titanomagnetite grains with dominant uniaxial anisotropy no combination of grain sizes (domain states) can explain Mrs/Ms values significantly above 0.5 . The similarity of hysteresis parameters for samples measured in different orientations effectively precludes grain alignment as a mechanism for producing the observed high $\mathrm{Mrs} / \mathrm{Ms}$ ratios. We have therefore argued that resolution of the high field and remanence data is best achieved by revision of the Mrs/Ms limit for SD titanomagnetites in MORB [Kent and Gee, 1994].

Hysteresis parameters for SD grains may be derived theoretically given a knowledge of the dominant type of anisotropy. Magnetic anisotropy may arise from magnetostatic, magnetoelastic, or magnetocrystalline energies, or a combination of these sources. The magnetostatic energy contribution in titanomagnetites is relatively small as a result of the low value of Ms (Table 1) and would be further reduced due to the decrease in Ms accompanying low temperature oxidation. The magnetization of Ti-rich members of the titanomagnetite series has therefore been thought to be controlled primarily by stress-induced anisotropy [O'Reilly, 1984; Özdemir and Moskowitz, 1992]. This interpretation is supported by the observation of complex domain structures in both synthetic and natural titanomagnetites [Halgedahl, 1987; Moskowitz et al., 1988], although the relevance of these observations on large grains to the remanence carriers in fine grained basalts is not necessarily straightforward. Both shape and stress-induced anisotropy are commonly regarded as having a uniaxial symmetry [Cullity, 1972]. Thus, an assemblage of randomly oriented, identical SD titanomagnetite grains whose magnetization is controlled solely by shape or stress-induced uniaxial anisotropy (or a combination of these) would have an Mrs/Ms ratio of 0.5 [Stoner and Wohlfarth, 1948; Cullity, 1972]. The high Mrs/Ms ratios of basalt samples in this study and those reported by Day et al. [1978] are therefore difficult to reconcile with uniaxial anisotropies alone.

Higher Mrs/Ms values may be produced by an important contribution from multiaxial magnetocrystalline anisotropy, which has a theoretical Mrs/Ms limit of $0.83\left(K^{\prime}>0\right)$ or 0.87 $\left(\mathrm{K}^{\prime}<0\right)$ [Joffe and Heuberger, 1974]. Differences in the corresponding $\mathrm{Brc} / \mathrm{Bc}$ ratios are relatively insensitive to the dominant type of anisotropy $\left(\mathrm{Brc} / \mathrm{Bc}=1.04\left(\mathrm{~K}^{\prime}>0\right) ; 1.08\left(\mathrm{~K}^{\prime}<0\right)\right.$, 1.09 (uniaxial); Joffe and Heuberger, 1974). Assessment of the relative contributions of uniaxial (stress-induced) and cubic (magnetocrystalline) anisotropy in titanomagnetites, however, is critically dependent on an accurate estimate of the level of stress and the effective magnetocrystalline anisotropy constant $\left(\mathbf{K}^{\prime}\right)$, which is in turn strain dependent [Ye et al., 1994]. Determinations of $K^{\prime}$ in titanomagnetites [Syono, 1965] indicate substantially different temperature dependencies for compositions near TM60. Recent determinations of $\mathbf{K}^{\prime}$ 
on titanomagnetite single crystals suggest low values (0.2-0.5 x $10^{4} \mathrm{~J} / \mathrm{m}^{3}$; Kakol et al., 1991; Sahu and Moskowitz, in press) for TM60, similar in magnitude (but of opposite sign) to those previously inferred for TM60 from Syono's classic study. The stress level in natural titanomagnetites has been correspondingly difficult to ascertain. Residual stress levels as high as $200 \mathrm{MPa}$ ( $2 \mathrm{kbar}$ ) have been inferred for synthetic samples [O'Reilly, 1984]. However, stress values of $<50 \mathrm{MPa}(500$ bars) have been reported for natural basalt samples [Appel, 1987; Halgedahl, 1987].

Özdemir and O'Reilly [1981] inferred $K^{\prime}$ values from hysteresis data on fine-grained (Al-substituted) titanomagnetites that are approximately an order of magnitude higher than those of Syono [1965]. These high $K^{\prime}$ values imply almost equal contributions from magnetoelastic and magnetocrystalline energies for stress values as high as $-200 \mathrm{MPa}$ and dominant magnetocrystalline anisotropy for lower stress values similar to those inferred for natural basalts (Table 1). Indeed, the maximum coercivities $(-100 \mathrm{mT})$ determined for our MORB sample collection are more than twice as large as the value predicted from stress anisotropy in basalts with residual stress values of $\sim 50 \mathrm{MPa}$. However, these high coercivity values are readily explained by $K^{\prime}$ values only a factor of 4 larger than typically inferred for TM60 from the single crystal data of Syono [1965], Kakol et al. [1991], and Sahu and Moskowitz [in press], and well below the values reported on fine grained material by Özdemir and O'Reilly [1981].

The high Mrs/Ms values observed in the present sample collection (as well by Day et al., 1978) point to a SD endmember with Mrs/Ms significantly above 0.5 . Under the assumption that shape and stress-induced anisotropy both have a uniaxial symmetry, these high $\mathrm{Mrs} / \mathrm{Ms}$ values require a substantial contribution from multiaxial magnetocrystalline anisotropy. Given the strong compositional dependence, direct determination of $\mathbf{K}^{\prime}$ for titanomagnetite compositions similar to those found in natural basalts $\left(\sim \mathrm{Fe}_{2.3} \mathrm{Al}_{.10} \mathrm{Mg} .05 \mathrm{Ti}_{.55} \mathrm{O}_{4}\right.$ for the present samples) would provide the necessary foundation for assessing the source of magnetic anisotropy in titanomagnetites, and hence a firmer basis for grain size/domain state inferences based on hysteresis data of titanomagnetite-bearing rocks. In the interim, the $\mathbf{K}^{\prime}$ values inferred from hysteresis data on synthetic Al-substituted titanomagnetites [Özdemir and O'Reilly, 1981] may provide the most appropriate estimate of the effective magnetocrystalline anisotropy constant for the variably oxidized natural titanomagnetites that account for the magnetic properties of fine-grained oceanic basalts.

Acknowledgments. We thank C. Langmuir, J. Bender, D. Christie for providing samples and major element geochemical data and D. Breger for assistance with SEM observations. D. Dunlop, A. Newell, B. Moskowitz, D. Schneider and S. Halgedahl provided helpful suggestions on the manuscript. C. Hunt provided high field data for selected samples. This research was supported by NSF grant OCE 94-02307. LamontDoherty Earth Observatory Contribution \#5319.

\section{References}

Appel, E., Stress anisotropy in Ti-rich titanomagnetites, Phys. Earth Planet. Int., 46, 233-240, 1987.

Christie, D. M., I. S. E. Carmichael, and C. H. Langmuir, Oxidation states of mid-ocean ridge basalt glasses, Earth Planet. Sci. Lett., 79, 397-411, 1986.
Collinson, D. W., Methods in Rock Magnetism and Palaeomagnetism, Chapman and Hall, Londor, 1983.

Cullity, B. D., Introduction to Magnetic Materials, Addison-Wesley, Reading, Massachusetts, 1972.

Day, R., M. D. Fuller, and V. A. Schmidt, Magnetic hysteresis properties of synthetic titanomagnetites, J. Geophys. Res., 81, 873-880, 1976.

Day, R., M. D. Fuller, and V. A. Schmidt, Hysteresis properties of titanomagnetites: grain-size and compositional dependence, Phys. Earth Planet. Int., 13, 260-267, 1977.

Day, R., S. Halgedahl, M. Steiner, K. Kobayashi, T. Furuta, T. Ishii, and A. Faller, Magnetic properties of basalts from DSDP Leg 49, Init. Rep. DSDP, 49, 781-791, 1978.

Dunlop, D. J., Developments in rock magnetism, Rep. Prog. Phys., 53, 707-792, 1990.

Gee, J., and D. V. Kent, Variations in Layer 2A thickness and the origin of the Central Anomaly magnetic high, Geophys. Res. Lett., 21, 297 $300,1994$.

Halgedahl, S., Domain pattern observations in rock magnetism: Progress and problems, Phys. Earth Planet. Int., 46, 127-163, 1987.

Joffe, I., and R. Heuberger, Hysteresis properties of distributions of cubic single-domain ferromagnetic particles, Philos. Mag., 29, 1051$1059,1974$.

Kakol, Z., J. Sabol, and J. M. Honig, Magnetic anisotropy of titanomagnetites $\mathrm{Fe}_{3-\mathrm{x}} \mathrm{Ti}_{\mathrm{x}} \mathrm{O}_{4}, 0 \leq \mathrm{x} \leq 0.55$, Phys. Rev. B, 44, 2198-2204. 1991.

Kent, D.V., and J. Gee, Grain size dependent alteration and the magnetization of oceanic basalts, Science, 265, 1561-1563, 1994.

Moskowitz, B. M., High-temperature magnetostriction of magnetite and titanomagnetites, J. Geophys. Res., 98, 359-372, 1993.

Moskowitz, B. M., and S. L. Halgedahl, Theoretical temperature and grain-size dependence of domain state in $\mathrm{x}=.6$ titanomagnetite, $J$. Geophys. Res., 92, 10,667-10,682, 1987.

Moskowitz, B. M., S. L. Halgedahl, and C. A. Lawson, Magnetic domains on unpolished and polished surfaces of titanium-rich titanomagnetite, J. Geophys. Res., 93, 3372-3386, 1988.

O'Reilly, W., Rock and Mineral Magnetism, Chapman and Hall, New York, 1984.

Özdemir, Ö., and B. M. Moskowitz, Magnetostriction in aluminum-substituted titanomagnetites, Geophys. Res. Lett., 19, 2361-2364, 1992.

Özdemir, Ö., and W. O'Reilly, High-temperature hysteresis and other magnetic properties of synthetic monodomain titanomagnetites, Phys. Earth Planet. Int., 25, 406-418, 1981.

Sahu, S., and B. M. Moskowitz, Thermal dependence of magnetocrystalline anisotropy and magnetostriction constants of single crystal $\mathrm{Fe}_{2.4} \mathrm{Ti}_{0.61} \mathrm{O}_{4}$, Geophys. Res. Lett., in press.

Soffel, $H$. , The single-domain-multidomain transition in natural intermediate titanomagnetites, Z. Geophys., 37, 451-470, 1971.

Stoner, E. C., F.R.S., and E. P. Wohlfarth, A mechanism of magnetic hysteresis in heterogeneous alloys, Philos. Trans. R. Soc. London, Ser. A, 240, 599-642, 1948.

Syono, Y., Magnetocrystalline anisotropy and magnetostriction of $\mathrm{Fe}_{3} \mathrm{O}_{4}-\mathrm{Fe}_{2} \mathrm{TiO}_{4}$ series, Jpn. J. Geophys., 4, 71-143, 1965.

Ye, J., A. J. Newell, and R. T. Merrill, A re-evaluation of magnetocrystalline anisotropy and magnetostriction constants, Geophys. Res. Lett., 21, 25-28, 1994.

J. Gee, Scripps Institution of Oceanography, La Jolla, CA 920930215 (email: jsgee@ucsd.edu).

D. V. Kent, Lamont-Doherty Earth Observatory, Palisades, NY 10964 (dvk@ldgo.columbia.edu).

(Received October 7, 1994; revised December 22, 1994; accepted January 4, 1995.) 